\title{
SELF-ASSESSMENT OF EXPERIMENTAL AND NUMERICAL COMPUTER MODELS DEVELOPED AT CISMID BASED ON A BENCH-MARK MODEL DEVELOPED IN JAPAN AT 1994
}

\author{
Victor ROJAS ${ }^{1,2^{*}}$, Carlos ZAVALA ${ }^{1,2}$ \\ ${ }^{1}$ Civil Engineering Faculty, National University of Engineering, Lima, Peru. \\ 2 Japan-Peru Center for Earthquake Engineering Research and Disaster Mitigation, Lima, Peru.
}

Received: 01/08/2019 Accepted: 12/08/2019

\begin{abstract}
This article reports the state-of-the-art of the implementation of finite element modeling for clay masonry walls under lateral loads. Important work had been developed at CIMID Laboratory of Structures in clay walls under lateral loads and, according to the review, nowadays, researches mainly report experimental tests with their numerical nonlinear models. This process is important to validate and complement their results. Bench-mark model developed in 1994 at Chiba University had been selected to evaluate all work developed at CISMID in these recently years. The evaluation uses three variables: 1) The study evaluated include experimental results for masonry walls, (2) The study evaluated use nonlinear models for interaction between mortar and bricks, and (3) The study evaluated record their results with graphics showing the failure process. Finally, evaluate these models with finite elements demand high costs because the hardware and software requirements. However, the acquisition of a computer for High Performance Computing is necessary to afford this kind of research.
\end{abstract}

Keywords: Finite Element, Nonlinear Analysis, Clay Masonry, Bench-mark.

\section{INTRODUCTION}

In Peru, since CISMID creation, 33 years ago, its Computer Room had been working on nonlinear geometrical and constitutive laws analysis on different materials at Graduate Program at UNI [1]. The level of nonlinear knowledge had been developed at to solving models from of NONSAP Program's exercise book which presented solutions from the whole exercises. At this point, computer students' work had to be evaluated with an Experimental Program to be tested at Structures Laboratory called at 2014: “Ing. Roberto Morales" working since 30 years ago.

The first work on Experimental and NumericalComputer Model was reported at University of Illinois [2]. Later on, others researches had worked, around the world [3-8]. The Experimental and NumericalComputer Model had been useful to understand much better behavior material and collapse patterns.

Increasingly, programs for Analytical Study of Materials Behavior are being used and their results are being interpreted without the full knowledge that the results entail by the approximations inherent to structural analysis. In the case of reinforced concrete that has been studied for decades there are assumptions that are implemented in relation to concrete cracking and concrete-steel adhesion. At DIANA ${ }^{\circledR}$, it is necessary around 20 parameters from masonry materials to model a structure in this material [9].

\section{THEORETICAL FRAMEWORK}

The resistance of materials indicates that the materials have an elastic behavior up to a certain value of stress or deformation [10]. From that point, the behavior is changed into another that is called nonlinear. This research has been presenting for this type of analysis: Analysis nonlinear of structures.

When it comes to the advanced analysis of structures, it is proposed that either the geometric configuration or the stress state of the structure is affected by loads beyond the usual.

In the case of geometric configuration, buckling is a clear case to mention. At local or global buckling, the structures resist the loads but with a different conformation of the load. Usually a suddenly collapse of the structure occurs.

\footnotetext{
* Corresponding author:

vrojasy@uni.edu.pe
} 
In the case of the efforts of the materials, most of the initial behavior is elastic and even linear can be mentioned. From certain levels of loads that are translated into stresses they constitute a different behavior in the deformations that make that no linear elastic constitutive law can be used.

Materials degeneration leads to the deterioration of materials [14]. In Figure 6 the degradation of the materials are visualized during the load cycles [4,14]. At $30 \mathrm{~mm}$ of displacement the admissible load in the experiment has been reduced in the order of $50 \%$, approximately.

Very good results since the 80 s have been obtained to model RC structures. The concrete walls have been models mainly with the distribution of structural steel as layers to represent its deformation [14]. In these times, commercial programs such as SAP2000 present this option [11].

\subsection{Computer Programs for Nonlinear Analysis}

Three factors are affecting the scientific development in the field of structural research during its non-linear behavior.

(1) The proliferation of low cost computers and little electronic capacity to work numerically data at double or more precision required.

(2) Illegal employment of the programs leads to professionals and students without sufficient experience you can make use of a tool of these characteristics.

(3) The lack of awareness to think that to make a computer model, at the same time they must be selected, or even manufacture instruments and/or measuring equipment with the numerical precisions that are needed according to the case

Nodaway, computer programs lead each other according their input and output data management. The following diagram is showing the minimum features to work on Experimental and NumericalComputer Model.

\subsection{Nonlinear Micro-models in Finite Element}

It can be in [14] that it was built and instrument to measure the mortar behavior to understand the load/displacement interaction to develop a computer model. This thesis had been applied this model but just only recommended data and some assumption.

By the other hand, computer programs works us Computer Aided Design entering to the computer any data on hand. Micro or macro-models or hybrid combination of both are employed to model structures. Macro models consisted into concentrate le maximum stress in some points (pinned plastic point is a well know example. Micro models consist that a mesh of finite elements will be part of the model with its on stress-strain curves. At the follow Figure 1 it will be showed masonry models using micro models.

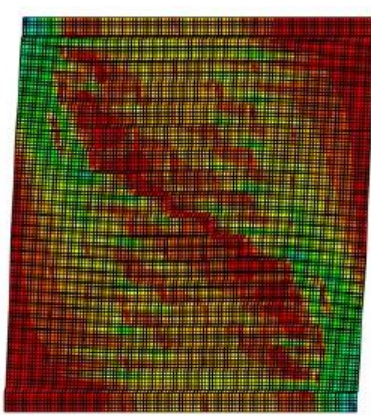

(a)

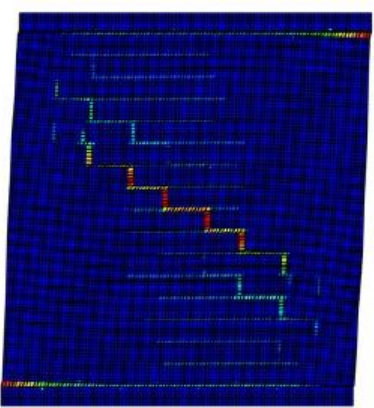

(b)
Figure 1. Result of micro models of masonry walls under shear loads. (a) Minimum principal stress components at integration points of the micro. (b) Maximum principal plastic strains at integration points of the micro-modelled wall. [12].

\subsection{Nonlinear Macro-models in Finite Element}

The macro models are being used by the rapid calculation required by these models. It is evident that the models will not obtain the distribution of efforts in the structural elements. However, these mathematical models allow the visualization of the global behavior of the structure. In many cases the obtaining of the load cycles is pursued to obtain the hysteresis behavior. At the Figure 2, it is shown the FE models without and with masonry panels.

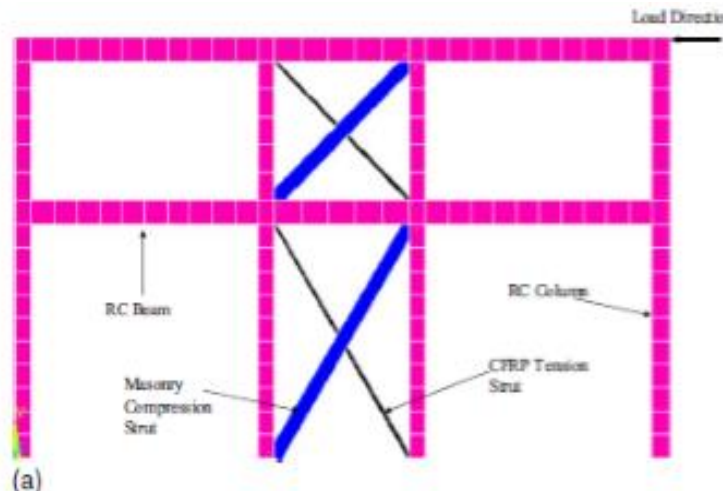

(a)

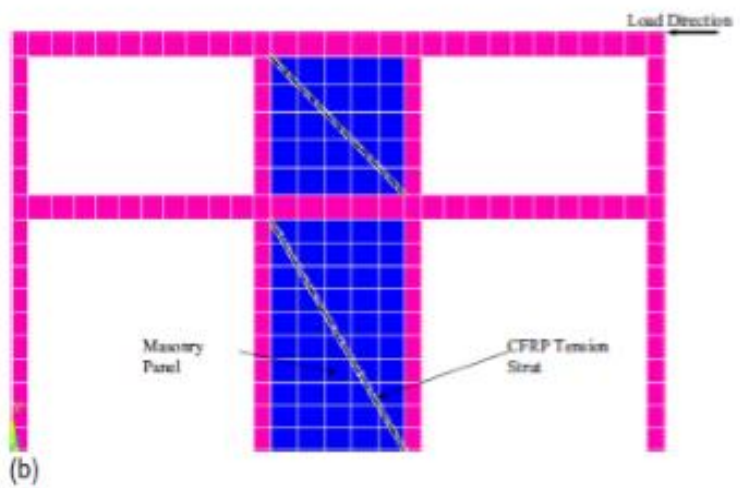

Figure 2. (a) Macro-models (b) Micro-models in the middle panel. [13] 
The Experimental and Numerical-Computer Model developed in Japan in 1994 has been considered as bench-mark in this work. The study and development work of the model took a full dedication time of nine months in total. The first six months were designated to acquire knowledge of the Experimental and NumericalComputer Model analysis. The last three months were designated to develop the computational analytical model, Analytical Study of Materials Behavior that represents the results acquired in the masonry walls.

The experimental data considered corresponded to laboratory tests carried out by the "Roberto Morales" Structures Laboratory of CISMID [4]. The stage in Japan corresponds in six months at the Institute of Building Research, BRI and three months at Chiba University, 1994 [14].

The proposal of this work consists of comparing the evaluation of the computer models used most recently in Japan. The work developed at the Chiba University in 1994 [14] is taken as a reference and compared with the work recently developed at UNICISMID*. All work that only develops the computational work and uses experimental results of other authors will considerate.

\subsection{Nonlinear Models for Different Materials}

Micro models are those that represent concrete and its stress-strain relationships in the integration points in each element of the finite element mesh. Depending on this, the typical stress-strain relationship is used and the results are corrected when the concrete material has already incurred in its non-linear behavior (Figure 3).

This, in turn, allows the development a crack distribution of previous similar test to incorporate as a cracking pattern in the developed structural model. A full knowledge of preliminary results allows to predict with better possibilities the prediction of the cracking patterns.

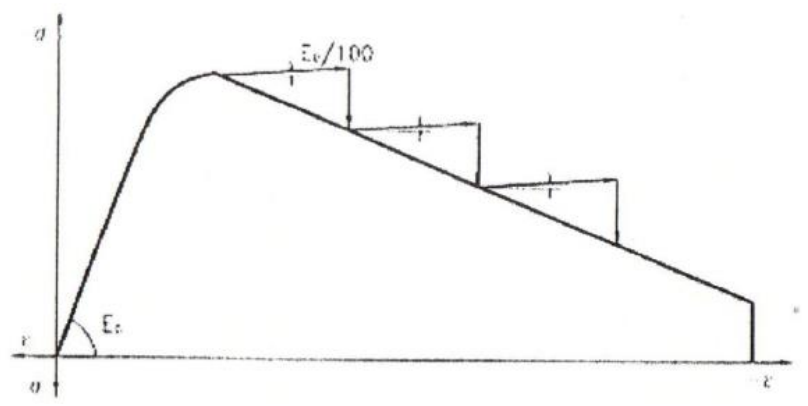

Figure 3. Technique Solution to downward at stress-strain curve $\{14]$
The nonlinear models for steel rebar, masonry bricks and mortar had been shown in [14].

\subsection{Numerical Methods for Nonlinear Analysis}

Three factors are affecting the scientific development in the field of structural research during its non-linear behavior.

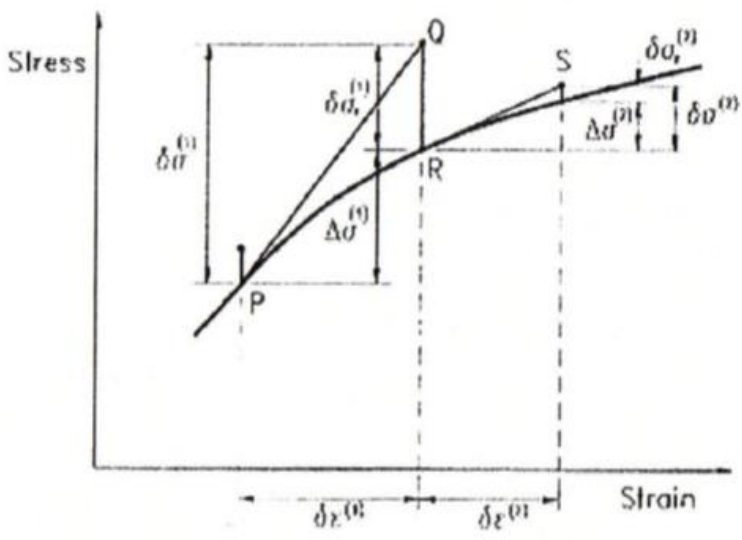
[14]

Figure 4. Unbalanced load iteration method - Constitutive level

Analytical Study of Materials Behavior consist in a pack of numerical methods to model constitutive laws of the different materials involve for the experimental model. After that, at structural level, the equilibrium has to take part form the correct stage according to the loading level (Figure 4).

\subsection{Models Evaluated with Benchmark comparing}

At followed it is presented all the Experimental and Numerical-Computer Model, Experimental and Numerical-Computer Model, models develop by CISMID during SATREPS ${ }^{\dagger}$ program and others researcher at FIC.

These five models represent part of the research that CISMID develop each calendar year since its creation as Research Centre (shown at Table 1).

Table 1. Experimental and Numerical-Computer Model, (CISMID, 2013-2019)

\begin{tabular}{|c|c|}
\hline $\begin{array}{c}\text { Technical report and } \\
\text { Author }\end{array}$ & Graphical representation \\
\hline
\end{tabular}




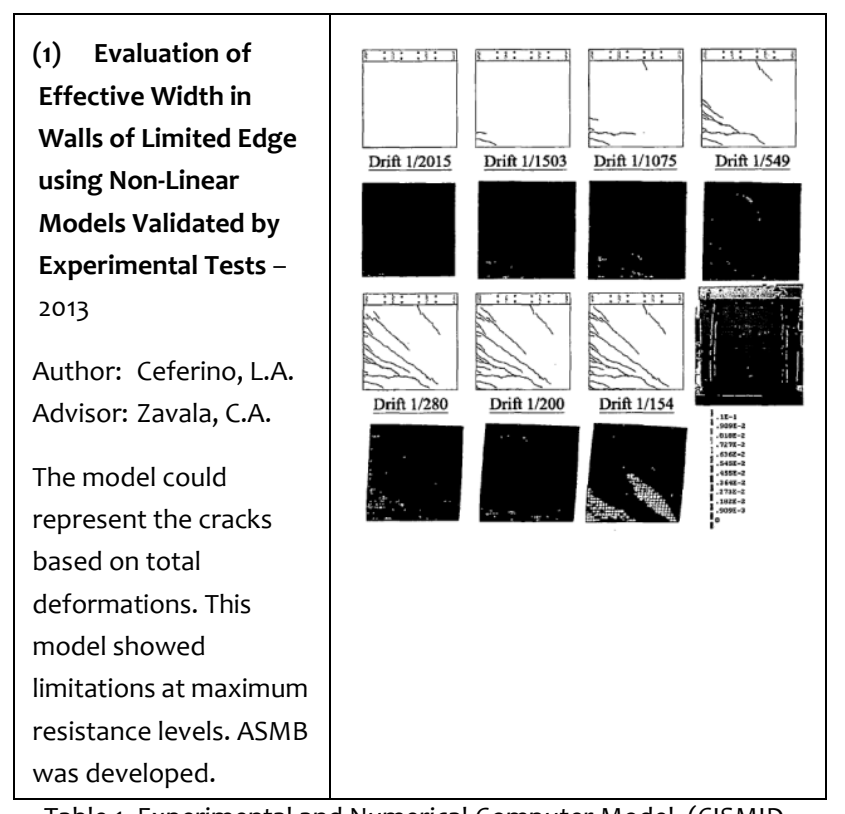

Table 1. Experimental and Numerical-Computer Model, (CISMID, 2013-2019) continuation

$\begin{aligned} & \text { Technical report and } \\ & \text { Author }\end{aligned}$
(2) Study of Non-
Structural Elements as
Filled Frame System
under Large Distortion
at natural Scale - 2015
Part 1. Graphical representation
Author: Zavala, C.A.
and Diaz, M.
The static full-scale
cyclic test were carried
out with the purpose
of knowing the
structural behavior of
the two floors
reinforced concrete
frame. These models
were tested without
infill masonry walls,
with infill masonry
walls and finally, with
reinforced infill
masonry walls.
(3) Study of the Wall
Behaviour of Walls of
Limited Ductility of 5
Level at half scale-
2015, Part 2. tests
Author: Zavala,
C.A. and Diaz, M.
Additional
experimental
were worked during

2015 with Limited
Ductility Walls of 5
levels at half scale. This
study involves the
development of an
experimental test and
a numerical simulation.
(4) Shear Resistance
by Adherence and
Friction in the joint
between mortar and
artisanal and industrial
clay bricks - 2016
Author: CISMID Staff
This study focuses on
joints resistance
between mortar and
the masonry units, for
this, masonry piles
subjected to direct
cutting tests were
used.
(5) Comparative
Capacitive Analysis of
the Capacity for a
Destructive
Earthquake in RC
Buildings - 2018
(TORRES, M. and
ZAVALA, E. 2018)
Compare someone
experimental results.

These five reports, with the exception of number (5), were developed basically as experimental analysis at the Laboratory of Structures in UNI-CISMID.

The next step is to compare the aims and goals of each project in terms of develop of numerical model for their understanding of structural behavior. These comparisons will be with the bench-mark model developed at Chiba University in Japan in 1994 


\subsection{Bench-mark Analytical Model}

The bench-mark model was developed in Japan. According to the information [14], the state of the art of the FEA techniques was established in the 90s. In Peru, the state of the art at that time was defined by the analysis of flat porticos of reinforced concrete or structural steel. The generation of plastic ball joints was formed when the structural elements struggled above the creep and with it, a failure pattern was formed by increasing the loads progressively.

These days, the non-linear analysis for professional projects is limited to the push-over analysis, and the use of dissipaters and insulators. In fact, many computer programs, especially the SAP2000, offer the possibility of modeling reinforced concrete walls with the option of sandwich-style material distribution. At the next chapter, those five examples with be evaluated in terms on the variables elected in order to validated our hypothesis. The following table is shown as the way how to evaluate at qualitative form (Example at Table 2):

Table 2. Marking score for the Self-assessment for each model develop at CISMID [14]

\begin{tabular}{|l|l|l|}
\hline \multirow{2}{*}{ Project } & \multicolumn{2}{l|}{ Comparison with bench-mark project $\left(^{*}\right)$} \\
\hline \multirow{2}{*}{$\begin{array}{l}\text { Scale } \\
\otimes \quad \begin{array}{l}(1 \text { is low, } 5 \text { is } \\
\text { high })\end{array}\end{array}$} & Variable (1) & $\otimes \otimes \otimes \otimes \otimes$ \\
\cline { 2 - 3 } & Variable (2) & $\otimes \otimes$ \\
\cline { 2 - 3 } & Variable (3) & $\otimes \otimes \otimes \otimes$ \\
\hline
\end{tabular}

$(*)$

Variable (1): The mathematical model contains material testing for a discrete analysis of the material.

Variable (2): Material Constitutive Laws were undertaken from own materials in Peru.

Variable (3): There is a convergence criterion to select the finishing of the calculations up to credible results.

\section{ANALYSIS AND RESULTS DISCUSSION}

\subsection{Data Analysis}

The five models had been compared with benchmark model and the results are shown in Table 3.
Table 3. Evaluation of the five models reported

\begin{tabular}{|c|c|c|c|}
\hline Model & \multicolumn{2}{|c|}{ Marking } & Comments \\
\hline \multirow{3}{*}{ Model 1} & (1) & $\otimes \otimes \otimes \otimes$ & \multirow{3}{*}{$\begin{array}{l}\text { This model it was developed in } \\
\text { DIANA }{ }^{\circledR} \text {. This software need } \\
\text { around of } 20 \text { parameters to be } \\
\text { incorporated in the model. }\end{array}$} \\
\hline & (2) & $\otimes$ & \\
\hline & (3) & $\otimes \otimes \otimes \otimes \otimes$ & \\
\hline \multirow{3}{*}{ Model 2} & (1) & $\otimes \otimes \otimes \otimes$ & \multirow{3}{*}{$\begin{array}{l}\text { Computer analysis by a FEA had } \\
\text { not be perform. In the second } \\
\text { part it was developed based on } \\
\text { this results. }\end{array}$} \\
\hline & (2) & $\otimes \otimes \otimes$ & \\
\hline & (3) & & \\
\hline \multirow{3}{*}{ Model 3} & (1) & $\otimes \otimes \otimes \otimes$ & \multirow{3}{*}{$\begin{array}{l}\text { Macro model was used in this } \\
\text { case. }\end{array}$} \\
\hline & (2) & $\otimes \otimes \otimes$ & \\
\hline & （3） & $\otimes \otimes$ & \\
\hline \multirow{3}{*}{ Model 4} & (1) & $\otimes$ & \multirow{3}{*}{$\begin{array}{l}\text { Excellent experimental } \\
\text { apparatus was developed to } \\
\text { know in detail the clay bricks } \\
\text { and mortar interaction. }\end{array}$} \\
\hline & (2) & $\otimes \otimes \otimes$ & \\
\hline & (3) & $\otimes \otimes \otimes \otimes$ & \\
\hline \multirow{3}{*}{ Model 5} & (1) & $\otimes \otimes \otimes \otimes$ & \multirow{3}{*}{$\begin{array}{l}\text { The elaboration of this analytical } \\
\text { results was based on Paper's } \\
\text { report. }\end{array}$} \\
\hline & (2) & $\otimes$ & \\
\hline & (3) & $\otimes \otimes \otimes$ & \\
\hline
\end{tabular}

\subsection{Results discussion}

It been identified that each model had been developed with different type of analysis. Model (1) used full micro-models to represent the walls. However, it had be developed the instrumental devices base on strange-gage and LVDT. Sensors for RC members had not be measurement. At the results of bench-mark model it was evident that the nonlinear response start in this position.

Models (2) and (3) worked very well as a sequence on an only one research. However, a simple nonlinear analysis took in place based in a macro model.

Model (4) is a good example as part of a big study program. The bench-mark model used a models from a reference to implement the clay brick with the mortar (Figure 2).

Model (5) worked with isolated base and it was executed based on Matlab ${ }^{\circledR}$ and Python which is an open computer programs.

Masonry bricks shear contact had be evaluated by using specific set up apparatus to analyze mortar behavior. (See at Figure 5). 


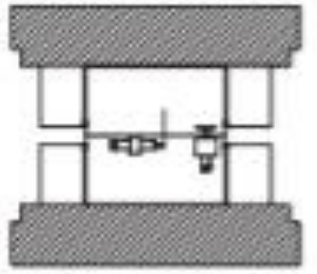

Elevation view

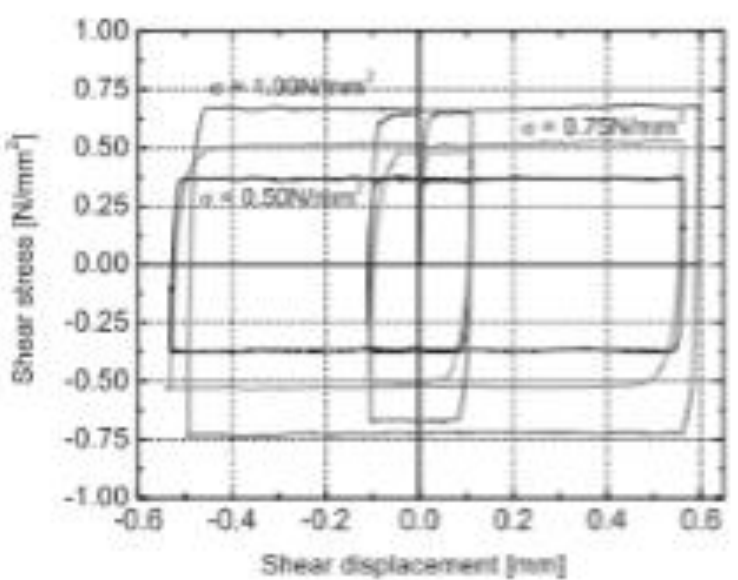

Figure 5. Equipment and Results of Atkinson's device for masonry mortar and bricks [14]

\subsection{Comments of the results}

According to the evaluated models (from (1) to (5)), in can be mentioned that it was identified isolated efforts to face nonlinear analysis models.

Those elements analyses mainly respond to the used of macro-models. However, if it is necessary to model shear walls or even RC elements, FEA has to be carried out to be compared with experimental results.

It is necessary to report a graph identifying cracking patters according to the increasing load in case if work with the enveloped curve as it is shown in Figure 6. To present a Figure in this format will be interesting to clarify the behavior specimen under lateral loads.

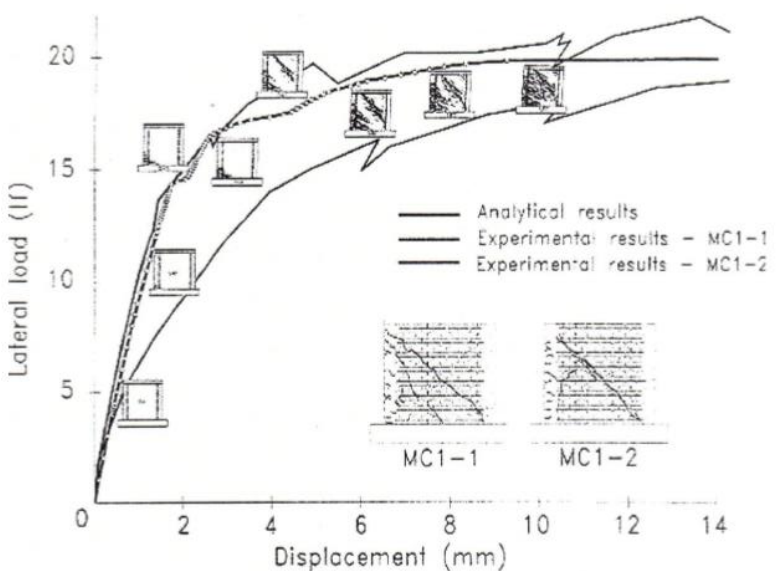

Figure 6. Comparison of Analytical and Experimental Results [10]

\section{CONCLUSIONS}

To introduce non-linear behavior for cracking, flexion and bonding, etc., specific lab tests have to be carried out to obtain these nonlinear characteristics of each material. The benchmarking model used only data of similar materials reported for different researchers.

These type of nonlinear analysis permit to visualize the distribution of cracks in whole model according to the monotonic loading pattern. Also, typical nonlinearities are identified such as the ductility of the steel bar at the left lower edge of the confinement reinforcement..

Software for Nonlinear Finite Element Analysis like DIANA, ABAQUS, MIDAS, and others, work well with micro-models to validate experimental results. However, hardware has to have high performance to save time.

\section{RECOMENDATIONS}

It is recommended that CISMID develop a masonry testing program consisting of determining some constitutive laws and bond and adhesion tests of our materials. In this way, their experimental tests activities will be strengthen.

Doctoral Program at Graduate School Unit at Civil Engineering Faculty needs to implement doctoral thesis by these steps: (1) Star with a preliminary experimental study measuring stress and displacement, (2) After that, a computer model has to be develop to study experimental results in detail and, (3) Finally, according to the need calibration, a final experimental model has to be elaborated using all previous understanding.

It is imperative to acquire a Super Computer in order to develop hard word computing for numerical model to complement experimental results which is still employed for this kind of research.

\section{REFERENCES}

[1] Piqué J R 1991 Advanced Analysis of Structures course. Universidad Nacional de Ingeniería. Lima

[2] Darwin D, Pecknold D A W 1974 Inelastic Model for Cyclic Biaxial Loading of Reinforced Concrete University of Illinois chapter 3

[3] Vecchio F J, Collins M P 1986 The Modified Compression-Field Theory for Reinforced Concrete Elements Subjected to Shear ACI Paper $\mathrm{N}^{\circ}$ 83-22

[4] Ramirez O 1994 Nonlinear Finite Element Analysis of Confined Masonry Walls Individual Studies at IISEE-BRI, 30 pp. 293-308

[5] Rojas V 1995 Análisis de Losas utilizando el Método de los Elementos Finitos Thesis for Professional Engineer-UNI, Peru 
[6] Noguchi H, Kashiwazaki T 2009 FEM Analysis of Interaction Effects of 3-D RC Members Subjected to Multi-Directional Cyclic Loading ASCE Structures Congress

[7] Ceferino L A, Zavala C A 2013 Evaluación del ancho efectivo en muros de ductilidad limitada de borde empleando modelos no lineales validados por ensayos experimentales Thesis Professional for UNI, Civil Engineering College, Peru

[8] Kumar K, Barbato M 2019 New Constitutive Model for Interface Elements in Finite-Element Modeling of Masonry, J. Eng. Mech., 145504019022

[9] DIANA 2014 DIANA FEA BV The Netherlands

[10] Wright W J, Askeland D R 2016 The Science and Engineering of Materials CENGAGE Learning, Seventh Edition ISBN: 978-1-30507676-1 USA

[11] Wang CY 2007 Pushover Analysis for Structure Containing RC Walls National Central University, Civil Engineering Department Taiwan
[12] Annecchiarico M F, Portioli F, Landolfo R 2010 Micro and macrofinite element modeling of brick masonry panels subject to lateral loadings, University of Naples, Italy [Reviewed on May 2019] at: https://www.researchgate.net/publication/289195463_Micro_an d_macro-

finite_element_modeling_of_brick_masonry_panels_subject to lateral loadings

[13] Erdem I, Akyuz U 2010 Analytical Investigation of Lateral Strength of Masonry In filled RC Frames Retrofitted with CFRP ASCE Journal of Performance of Constructed Facilities, 24 (4) ISSN 0887382820104 DOI: 10.1061/_ASCE CF.1943-5509.0000113

[14] Rojas V 1994 An Analytical Study of Behavior of Confined Masonry Structures under Lateral Loads Noguchi's Laboratory at Chiba University Japan 